\section{IN THIS ISSUE}

\section{From the Field}

A recent case involving a University of

Michigan student accused of sexual mis-

conduct illustrates the need to provide

responding parties with adequate notice.

Page 2

Compliance Corner

Consider the best strategy for investigat-

ing and adjudicating cases with a single

respondent but multiple reporting parties.

Pages 4-5

\section{Professional Perspective}

Holly Gorski, the Title IX coordinator and vice president for human resources at

Pierce College, talks about her role in

promoting an inclusive restroom policy.

Pages 6-7

\section{Resource Alert}

Understand the interplay of FERPA and

Title IX when it comes to records created

and maintained as part of a Title IX-related

incident.

\section{Page 8}

\section{ABOUT US}

The NCHERM Group, LLC., a law and consulting firm offering systems-levels solutions to create safer campuses, and the Association of Title IX Administrators, which provides networking and professional development for Title IX coordinators, publish Title IX Today and its companion e-newsletter.

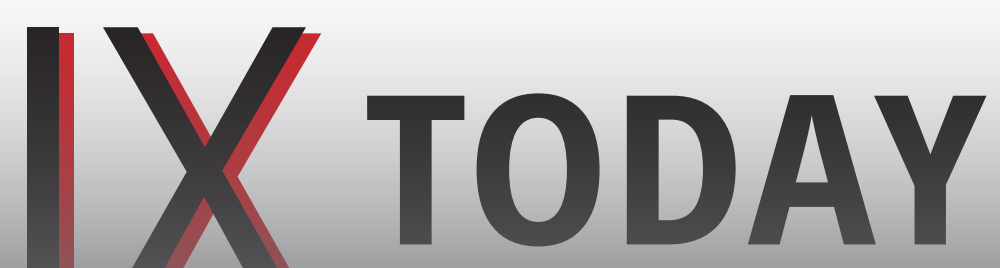

THE LEAD I POLICIES \& PROCEDURES

\title{
Address most stalking cases through an equity lens to ensure VAWA compliance
}

ByLeslee Morris, J.D., ContributingEditor

T $\mathrm{n}$ the spring of 2011, higher education professionals were processing the recently released Office for Civil Rights Guidance on Sexual Violence when we caught wind of the proposed Campus Sexual Violence Elimination Act, dubbed SaVE, which had been introduced in late 2010. The passage of SaVE would, among other things, require institutions to include incidents of stalking and relationship violence in their Annual Security Reports and to resolve those incidents through the 'The best approach at this time is to use the equity lens for the vast majority of stalking and relationship violence cases.'

- Morris all are. Title IX requires an equitybased response only when gender or sex is the basis for the alleged misconduct, but VAWA mandates equity provisions in any stalking or relationship violence case. The best approach at this time is to use the equity lens for the vast majority of stalking and relationship violence cases.

People tend to think of stalkers as strangers who are obsessed with someone with whom they've had only superficial interactions, if any. But more than 80 percent of campus stalkequity lens we were starting to apply ing victims were acquainted with their to sexual violence cases. Prior to SaVE, stalkers, according to a report pubneither stalking nor relationship vio- lished by the National Criminal Justice lence had been addressed in a meaningful way by OCR in its official guidance documents.

SaVE was incorporated into the reauthorization of the Violence Against Women Act, which passed in 2013. Many saw VAWA and Title IX as two flagpoles holding up the banner of gender equity. Yet the inclusion of all stalking and relationship violence, without a nexus connecting the causation of those incidents to gender or sex, seemed somewhat confusing. Although the majority of these cases are likely to be gender- or sex-based, not
Reference Service. In fact, the vast majority were current or former intimate partners or acquaintances. And stalking is more common that you might think. That report, titled "Extent and Nature of the Sexual Victimization of College Women: A National-Level Analysis," indicated that more than 13 percent of college women had been stalked during the previous academic year. In many cases, stalkers are motivated by obsession and a desire for control, which stem from either a real or imagined relationship with their victims.

Continued on p. 3 


\section{TITLE|X TODAY \\ FROM THE FIELD \\ Case illustrates need to provide parties with adequate notice}

Publisher Brett A. Sokolow, J.D.
Brett@ncherm. org

Editor

Cynthia Gomez, M.A.

Cynthia@ncherm.org

Assistant Editor
Marianne Price, M.S.

Marianne@ncherm.or

Contributing Editors Leslee Morris, J.D.
Erin Buzuvis, J.D.

Nancy Hogshead-Makar, J.D.

\section{Title IX Today (Print ISSN 2377-
8725 Online ISSN 2377-8733; DOI:
10.17732TIXT) IS}

(10.17752 The NCHERM Group, LCC

109 Lancaster Ave., Berwyn, PA
19312.

ANNUAL SUBSCRIPTION:

\$299: Includes one issue per month,
sent via postal mail and emailed in PDF

format, along with additional premium

TO ORDER:

Phone: (610) 993-0229

Email: Amanda@ncherm.org
URL: www.ncherm.org/store

Postmaster: Send address changes to

Titte IX Today, The NCHERM Group, LLC.,
1109 Lancaster Ave., Berwyn, PA 19312 .

Copyright @ 2015 The NCHERM Group, mitted by the 1976 United States Copyright Act, no part of this publication may
be reproduced or stored in a retrieval be reproduced or stored in a retrieva
system in any form or by any means system in any form or by any
without prior written permission.

Reprint requests may be sent directly
to Cynthia@incherm.org Reprint autho to Cynthia@ncherm.org. Reprint authorization may also be acquired through
payment of a per-copy fee to the Copy
right Clearance Center, located at 222 right Clearance Center, located at 222
Rosewood Dr., Danvers, MA 01923. Rosewood Dr., Danvers, MA 01923.
Phone: (978) 750-8400; Fax (978) 646
By Cynthia Gomez, Editor

to the university at Eni- the end of his suspension. ThroughA versity of Michigan student out all university proceedings, Sterwho was accused of engaging rett raised concerns of procedural due in sexual misconduct and suspended process violations.

highlights the need to give students While most of the procedural due appropriate notice before questioning process claims he asserted in his lawthem about potential policy violations suit (Sterrett v. Cowan, et. al (United so that they can prepare and secure an States District Court, E.D. Michiadvisor, if they so choose.

Drew Sterrett was an engineering 2015)) fain Division, February 4 sul sexul intercurse After leaving of the charges agins him pror campus following the After leaving of the charges against him prior to campus following the completion of that initial investigatory interview. his freshman year, he was contacted "[T]he stronger the private interest. by the school regarding the complaint the more likely a formal written notice against him. He was interviewed - informing the accused of the charge, about the incident the same day via the policies, or the regulations the acSkype, even though he was not told cused is charged with violating, and a what the specific allegations against list of possible penalties - is constituhim were.

Following an investigation, the institution proposed a resolution agreement that would have required Sterrett to admit to sexual misconduct an be suspended. He refused to accept the agreement. Nonetheless, he was suspended. He appealed the decision, and a university appeals board lessened the suspension period but required that he admit to sexual misconduct if he

\section{EDITORIAL ADVISORY BOARD}

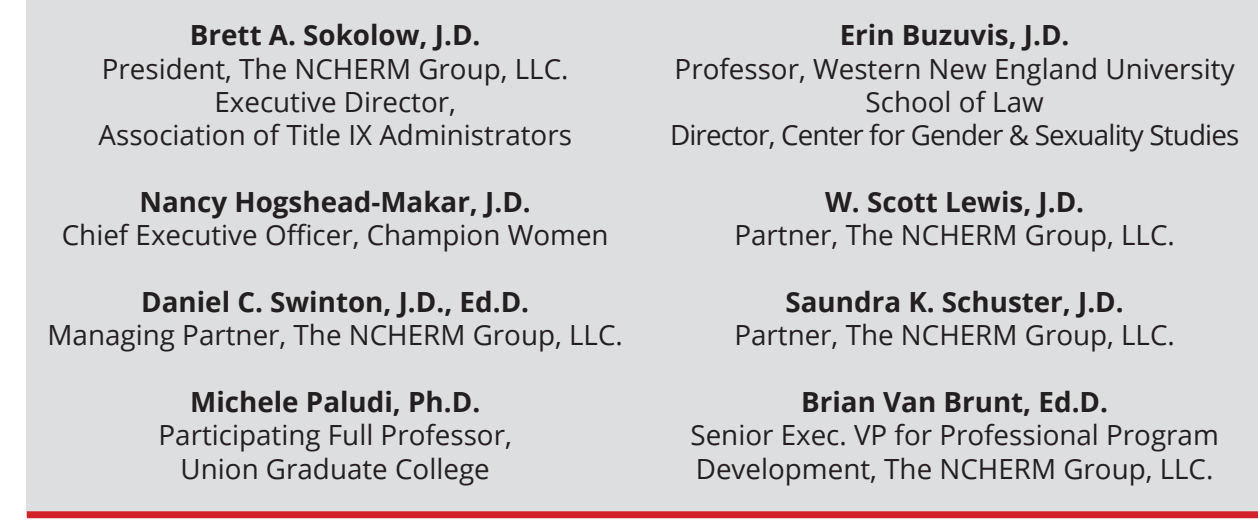

Continued from p. 1

The college environment is ripe for stalking-type behavior. The selfcontained nature of the campus makes it easy to determine individuals' schedules. And predictable class and work schedules makeiteasy to follow or watch individuals as they move about. Plus, stalkers can readily find information about a student or employee through the campus directory. Access security to buildings is often lax. In addition, the campus is a socially interactive environment, where students are often receptive to interactions with loosely connected acquaintances and strangers. Finally, as savvy internet users, college-aged stalkers have seemingly limitless platforms to contact their limitless platforms

The reauthorization of VAWA uses the definition of stalking from the 1994 version of the law. Stalking is defined as engaging "in a course of conduct directed at a specific person that would cause a reasonable person to fear for the person's safety or the safety of others; or suffer substantial emotional distress." A course of conduct is "two or more acts, including acts in which the stalker directly, indirectly, or through third parties, by any action, method, device, or means, follows, monitors, observes, surveils, threatens, or communicates to or about a person, or interferes with a person's property." A reasonable person is defined as "a reasonable person under similar circumstances and with similar identities to the victim." And substantial emotional distress is "significant mental suffering or anguish that may, but does not necessarily, that may, but does not necessarily, require medical or other
treatment or counseling."

treatment or counseling.

We've heard criticism of this definition. Some victim advocates worry that it is too narrow. They believe that college-aged students who are being stalked may not identify with the "fear" "substantial emotional distress" elments. For example, a 19-year-old ho is being stalked may take a differtroute to class, avoid the gym, and elete an online profile, but may attribute those changes in behavior to annoyance or over-caution, and may not readily identify with the concepts of fer or substantial emotional distress. Some colleges simply state in thei policies that emotional distress in cludes those situations in which one person substantially alters everyday activities as a result of the unwanted course of conduct. However, others fear that this definition is overly road, and may unintentionally encompass some behaviors that more likely result from social awkwardness or a disability like autism-spectrum disorder rather than an obsession ased in fantasy or a desire to control former partner. Some suggest that, like many criminal statutes, the stalking definition should require that the course of conduct only constitutes stalking when done in a menacing manner or with intent

Recent revisions to the ATIXA model policies include two levels of stalking to reflect the variation in behavior. Stalking 1 is defined as "a course of conduct directed at a specific erson on the basis of actual or pereived membership in a protected class that is unwelcome and would cause a reasonable person to feel fear." Stalking 2 is defined as "repetitive and menacing pursuit, following, harassing, and/ or interfering with the peace and/or safety of another."

We suggest that institutions consider incorporating these two versions of stalking into their policies to comprehensively address stalking while simultaneously recognizing that behaviors and asses a wide array of

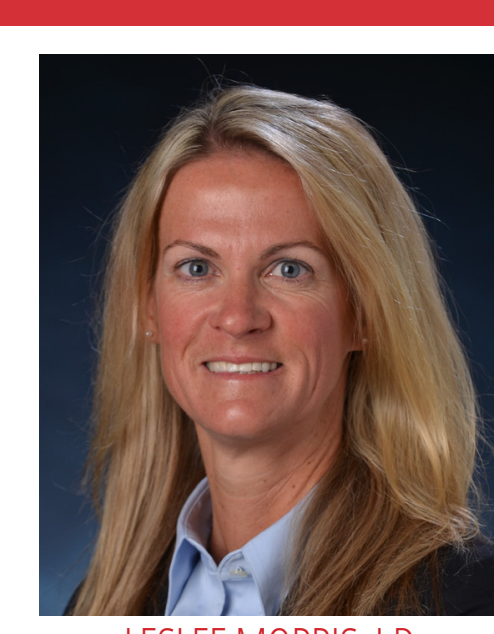

EESLEE MORRIS, J.D.

Leslee Morris is an associate at The NCHERM Group, LLC. She was previously a Title IX compliance and grievances coordinator for National University. You may contact her at Leslee@ncherm.org.

\section{KEY TAKEAWAYS}

"While stalking may conjure images of strangers lurking behind windows and street corners, many stalkers are intimate partners or former partners of their stalking obsessions.

1 The self-contained nature of the campus environment, predictability of individuals' schedules, often-lax building security, and the tech savvy of today's students make stalking particularly easy.

1) To address concerns with existing definitions of "stalking," ATIXA separated stalking into "stalking 1," which covers more benign behaviors, and "stalking 2," which involves more menacing conduct. $\diamond$ 


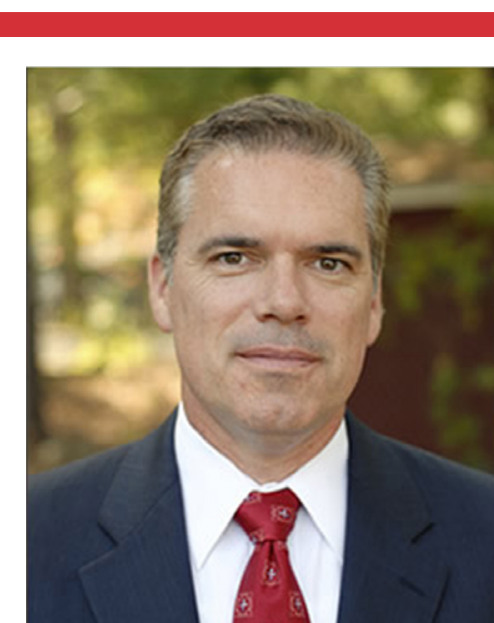

W. SCOT LEWIS, J.D.

W. Scott Lewis is a partner at The NCHERM Group, LLC. and a cofounder and advisory board member of the Association of Title IX Administrators. He can be reached at Scott@ ncherm.org.

\section{KEY TAKEAWAYS}

" Each case will require individual consideration about whether a single investigator whether a single investigator
or team is most appropriate. or team is most appropriate. " Some factors to consider in determining whether to connect investigations are: prox imity in time and distance between incidents; whethe behavior has a similar MO or is indicative of a pattern; and what the parties want to see happen.

" The college, not the parties, gets to decide how cases are

"Whether different allegations against a respondent are adjudicated together or separately depends partly on the adjudication model used by an institution. $\diamond$

\section{COMPLIANCE CORNER I INVESTIGATIONS \& HEARINGS}

\section{Strategize approach for cases involving} multiple allegations, single respondent

\section{ByW.Scott Lewis, J.D.}

ndividuals who commit sex-based offenses often continue to offend until caught. Research has proven this, and the recent allegation against Bill Cosby come to mind as a case in point. In the college setting Title IX administrators must determine how to best handle case involving allegations against a single responding party by multiple reporting parties. For instance, should the me investigator(s) look into all the cases? And should there be a djudication process (or hearing) for all the allegations?

Unfortunately, there is no one ap proach that applies best every time. Rather, each case will require individual consideration about what strategy might be most appropriate. Some factors to consider in determining the answers to those questions include proximity in time an distance between incidents; whether behavior has a similar modus operandi, or MO, or is indicative of pattern; and what the parties would like to see happen.

Let's first review some easier case in which multiple allegations would likely be best handled by the sam investigator(s)

1. A student is alleged to have assaulted two women in the same night and in the same room, apartment, or house. Here, the time and geograph proximity are so close that the incidents can't really be separated.

2. A professor is alleged to have made harassing comments or touched multiple students inappropriately in class. Again, because of the time and locatio proximity, the allegations can't really be treated as standalone incidents.
But what if those cases involved allegations of misconduct occurring over weeks, months, or even years? Is it still appropriate for the same investigator(s) to look into all the allegations? It depends.

Consider your office's resources. A small campus that has just a few trained investigators (or only one) won't have any real choice here. But if you have the latitude to choose whether or not to assign different investigators to different allegations, ing the advantages and disanges of using the same investigators. One of the biggest pros of using the same investigators across allegations is that investigators will be in a good position to recognize any patterns or similarities in MO that may be present. However this could also be addressed by having investigators probing different allegation share relevant information with each other.

Using the same investigator(s) for multiple allegations against a single respondent can also help to develop a good rapport with that party. Put Would you team of investigat epeating to keep repeating the same information to multiple investigative teams?

Using the same investigators can promote good rapport with the reporting parties as well, which can speed things up. If those parties know that investigators are looking into multiple complaints (and they likely will), feelings of embarrassment or shame may be minimized, and they may feel more inclined to ensure the reporting party doesn't get the chance to re-offend. yourself in that individul's shoes.
As a result, important details may be shared with less hesitation.

On the other hand, one key disadvantage to using the same investig tors for different allegations involv ing the same respondent has to with resource depletion and the appearance of inefficiency, especially

if your investigators are volunteers.

But a bigger concern with this approach is that a responding party may feel that getting a fair shake is not possible. In other words, the respondent may feel that since an nvestigator or investigative team believes that party to have committed one offense, it will render a finding of responsibility in all other allegations. The responding party's attorney may also question investigators' impartiality if they investigated all the allegations. Should a case go to court, an attorney may rgue that there's no way for investigators to be impartial because their findings in one investigation will tint their views in subsequent investigations.

As you can see, this is a determination that must be made on a caseby-case basis. The closer alleged incidents are in time and geography, the more likely that a single investigator or investigative team is the best approach. A dramatically similar MO, even between incidents occurring over a long period of time, may the preferred strategy.

What about parties' wishes?

What happens if reporting parties disagree with your chosen approach? Let's say that the reporting parties (or their parents, partners, or attorneys) don't want a single investig tor or team probing multiple alleg tions? Some parties (reporting and responding) may use this to set up a potential bias claim later.

Neither the reporting parties no the responding party gets to decide how the institution investigates, an more than they would decide the timelines, order of interviews, or djudication techniques. The institution simply needs to be sure that has taken steps to proactively address ny issues that the parties might bring up.

Some may be concerned that eporting party who objects to an stitution's investigative approach might simply opt out of participating in the process. Reporting parties pt out of the process for numerous reasons (e.g., climate, possible outcomes, emotional toll, etc.), but institutions must still proceed as best sthey can to protect their campus communities. They must document nd explain the rationale for the choices they make, but they still get make those choices.

Adjudication options

\section{Aepend on model used}

Once the question of how to invesgate has been answered, the question of how to adjudicate such cases must be tackled. Should there be muliple hearings, or just one? This may e dependent on the adjudication model used by the institution, and can e particularly tricky if it uses different processes for different types of of fenses. Again, there is not an absolut right answer here.

If a college uses a pure investigator model, where the lead investigator is the adjudicator, the college made the ecision to connect the adjudication when the decision to join the invesigations was made, so the concerns mentioned earlier should have bee already addressed. institutions that some of the questions most likely to use an adjudication model where come up. mendations to others for administrative adjudication? If allegations have been joined, that report should articulate the rationale for that and in clude a statement that while pattern behavior or proximity in time and/ or location should be considered and weighed, a finding of responsible/ not responsible on one allegation me finding on other allegations. To be clear, this applies for adjudication model that don't include re-interviewing or open testimony, but simply a review of the investigation report and sanctioning recommendations.

It's with the traditional hearing panel model that myriad concerns tend to surface. For one, there are logistical issues to consider. For in stance, a room may be too crowded, complainants may need to be rotated into the room, and information sharing may cause FERPA concerns. Then there's the very real concern that it could appear as if the institution is uniting against the responding party.

If different allegations have been joined, the panel will need to be very well trained on how to consider evidence, weigh different findings, and assess credibility. It should also have a sound understanding of patterns and predation. If different reports haven't been joined, the college will have to determine if it will (or can) use the same panel members, or whether that wor

This article doesn't cover all of the issues that could arise when faced with cases involving multiple reporting parties. But hopefully, it has given 


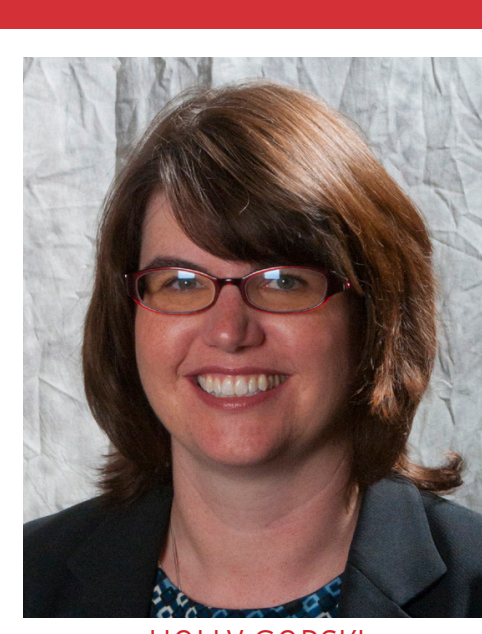

HOLLY GORSKI

Holly Gorski serves as the Title dent for human resor college in Washington State.

\section{KEY TAKEAWAYS}

"A policy of allowing ind viduals to use whichever restroom best aligns with their gender identity and providing gender-neutral policies demonstrates a focus on inclusiveness.

» Having an inclusive policy is not enough; that policy must be well communicated to members of the campus community.

"Answer questions and/o complaints about restroom usage by transgender individuals clearly and directly to avoid confusion.

" Transgender restroom access is an issue of great importance to those impact tance to those impacted by on a daily basis, and must not of other Title IX issues. $\diamond$
PROFESSIONAL PERSPECTIVE I POLIIES AND PROCEDURES

Restroom usage questions, complaint provide chance to promote inclusiveness

ByErinBuzuvis, J.D.,ContributingEditor email was a reminder of guidance the $\mathrm{n}$ last month's issue of Title IX state had already provided to employToday, I addressed Title IX's appli- ers and the public.

cation to sex-designated restrooms The email was sent to all the emchlock reoms and presented some ployeer deas for prove sion. As a follow-up, I interviewed student employees, of course, so in that Holly Gorski, the Title IX coordinator way it also got out to students, but the and vice president for human resources message was intended for employees. at Pierce College, a community college Your email was prompted by in Washington, about implementing "questions from the college an inclusive restroom policy. This year, you sent out an individuals and restroom use." email to faculty and staff What kind of questions had you saying, "Recently we have received received? questions from members of the college $A$ Over a period of about four to community at both Fort Steilacoom and $A_{\text {six weeks, Human Resources re }}$ Puyallupabout transgenderindividuals ceived two inquiries from employees and restroom use. The short answer is at different campuses and an anonythat every member of the Pierce College mous complaint from someone who crom align with their gender ideni- id stroom aligns with their gender identi- questions were along the lines of, "Is ty. Pierce College is also in the process of there a rule about which restroom identifying gender-neutral restrooms transgender person should use? onboth campuses, which willbe available When the first question came in for anyone to use, regardless of gender we answered it without wondering too identity or expression. It is not up to oth- much about it, since we in HR routineer people to determine whether or not a ly field questions about campus rules given person is in the "righ" restroom a ly fictices. When we got the second If anindithe question, we thought it was odd timstroom, it is the right restroom for them. ing, but because the second question (In the rare event that they entered the came from a different location, we restroom by mistake, they will certainly couldn't tell if it was a coincidence or exit upon realizing the mistake without cause for concern. When we got the any outside help.)" What was your complaint, which was essentially about intention with this email? the college's (perceived) policy of forcMy goal with that email was not ing individuals to use the restroom A to create a new policy, but to that aligned with the gender assigned explain the administration's under- at birth, we thought, "Whoa! We have standing of our existing legal obliga- to correct this." The anonymous comtions under Title IX as well as Wash- plaint had been sent to multiple adington State law, which has included ministrators. We discussed it as an adsexual orientation and gender identity ministrative team and decided to send and expression as protected classes something out right away. The email since 2006. From our perspective, the was the result. What experiences or resourc-
es did you draw upon in hanthis situation?

I had some experience with an Aemployee in transition while I was working for a previous employer, so I already knew that the Washington State Human Rights Commission, the agency that enforces the Washington Law Against Discrimination, has a good Q\&A for employers and others on its website. Since I am anso Pirce College's Title IX coordinator, I knew that Title IX covers gender identity, so that Title IX covers gender identity,

looked for guidance there as well.

I felt like I had a good grasp of the female, I knew that there were many other things I did not understand about this topic. So I spent time reading online resources for transgender people and allies, paying attention to concerns around restrooms and general tips for language use. I did not want to inadvertently offend transgender individuals while trying to discuss this topic.

What reaction did you get from the college community in response to this email?

$A$ Several people responded to the Aemail, either by replying to all or to me directly. The majority of the comments were supportive. I did receive some responses expressing concerns, and a very small number from individuals who felt the topic was offensive.

The Pierce College Puyallup Umbrella Club (a student group) published the email on its Facebook page in March and took on "safe restrooms" as a public awareness topic in Spring quarter. The Fort Steilacoom student newspaper, The Pioneer, ran a news article and a positive opinion piece on the topic in April.

In May, the college offered training sessions about meeting the needs of transgender students at both staff and faculty in-service days. The staff who is transgender and the faculty dressing this? session was taught by one of our own faculty members whose current sabatical is related to transgender issues. These were pieces of a larger training ffort on diversity and equity issues we did all year and will continue to focus on next year.

What feedback have you gotten from outside the Pierce College community?

A All the outside feedback we've A heard or read has been positive. The first outside contact I received rearding this surprised me because at hat point I didn't know anyone had put it on Facebook or that anyone ther than college employees were aying attention. A local website called The Pierce Progressive let me know tha student had sent it the email and it as running a story on it. Then later, arned it had been published on Facebook and The Title IX Blog.

Aitle IX compliance efforts right Anow are largely focused on preventing sexual violence. That's very important, and something like transimportant, and something like trans-
gender restroom access may seem small in comparison. But it's hugely important on a practical, day-to-day

evel for the people it impacts.

We also learned about the importance of communication. I don't bewas intentionally trying to do the wrong thing when it came to restroom access, but apparently there was confusion about how we implemented that aspect of the law, and we may have avoided that confusion with proactive, specific communication.

\section{About the Author}

Erin Buzuvis is a professor at the Western New England School of What did you learn from this Law. She also serves as the director experience that you believe of the Center for Gender \& Sexuality would be helpful for other Title IX Studies.

\section{TITLE |X TODAY SUBSCRIBE TODAY}

$\square$ Yes, I'd like a one-year subscription to Title IX Today, which includes one eight-page issue per month, in print and PDF, along with access to additional premium content delivered via email, all for just $\$ 299$.

Simply fill out this subscription coupon with your information and payment

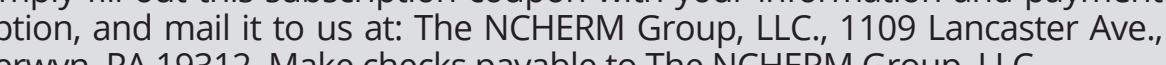

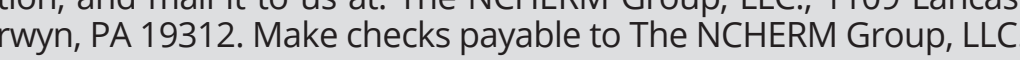

Name:

Title: Card \#: $\quad$ Expiratio $\square$ Check is enclosed. $\square$ Amex $\square$ MC $\square$ Visa

Mailing Address: Expiration: Cardholder Name:

Signature:

Email:

Phone: Marianne@ncherm.org.
Mare email 


\section{IIILLEIXIODAY}

\section{Understand the interplay of FERPA and Title IX}

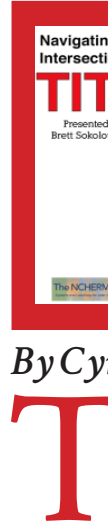
Navigating the
Intersection of TITLEIX R\& P A

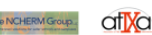

\section{LEARN MORE}

To learn more about The NCHERM Group's "Navigating the Intersection of FERPA and Title IX," please visit www.ncherm .org/online-trainings/recent-online-trainings/\#ferpa. $\diamond$ official never creates a written or recorded record of statements made by a reporting party, those statements fall outside FERPA's bounds. Still, Title IX protects them even if FERPA does not.

A point to remember is that FERPA deals with privacy, which is a legally conferred status is less strict than the confidentiality, which attaches to privileged records in law, counseling, etc. While OCR talks about "confidentiality" under Title IX, that law has no confidentiality requirement, so OCR really means "privacy." Other topics covered are the dos and don'ts for respondent access to complaints; gag orders and the need to maintain "confidentiality" under Title IX; and balancing a student's FERPA rights with the institution's Title IX obligations. $\diamond$ 